\title{
PERCEPÇÃO DOS PAIS SOBRE A PARTICIPAÇÃO NA ESCOLA PÚBLICA: UMA PESQUISA BIBLIOGRÁFICA
}

\author{
Pamela Tamires Belão Fernandes, Yoshie Ussami Ferrari Leite
}

Universidade Estadual Paulista - UNESP, Programa de Pós-Graduação em Educação, Mestrado em Educação, Presidente Prudente, SP. E-mail: pa.tamiresls@gmail.com. Agência de fomento: CAPES

\begin{abstract}
RESUMO
A democratização do ensino trouxe a escola novos sujeitos, tornando-se necessária a participação destes no processo de organização da mesma. Este estudo trata-se de um recorte de uma pesquisa, tendo o objetivo deste estudo foi investigar a produção acadêmica sobre a percepção dos pais sobre a participação na escola. A metodologia constou de uma pesquisa bibliográfica em dissertações e teses de Programas de PósGraduação em Educação (PPGE) com conceitos de 4 a 7 (Capes), no período de 2003 a 2013, com o uso de descritores. Para a análise fizemos uso da análise de conteúdo dos resumos. Como resultados, obtivemos 74 PPGEs e por meio de descritores encontramos 277 trabalhos. Os resultados apontam que os trabalhos encontrados possuem pontos específicos da participação dos pais na escola e com um projeto políticopedagógico articulado. Concluímos que em nenhum dos trabalhos a percepção dos pais foi abordada, se mostrando uma temática da pesquisa relevante.
\end{abstract}

Palavras-chave: pesquisa bibliográfica, pais, participação, gestão democrática, escola pública.

\section{PERCEPTION PARENTS FOR PARTICIPATION IN PUBLIC SCHOOL: A RESEARCH LITERATURE}

\begin{abstract}
The democratization of education has brought new school subject, making it necessary for their participation in the process of organizing it. This study deals with a part of a research, with the objective of this study was to investigate the academic research on the perception of parents on participation in school. The methodology consisted of a literature search in dissertations and Graduate Programs thesis in Education (PPGE) with concepts from 4 to 7 (Capes), in the 2003-2013 period, with the use of descriptors. For the analysis we used the summaries of content analysis. As a result, we obtained 74 PPGEs and through descriptors found 277 works. The results show that the works have found specific points of parental participation in school and with an articulated political-pedagogical project. We conclude that none of the work the perception of parents was addressed, showing a thematic of the relevant research.
\end{abstract}

Keywords: bibliographical research, parents, participation, democratic management, public school.

\section{INTRODUÇÃO}

O processo de democratização do acesso ao ensino ocorrido somente nas últimas seis décadas ocasionou uma transformação da escola pública brasileira. A partir dessa transformação, as portas da escola foram abertas a um alunado oriundo da classe popular, momento que a escola deixou seu caráter elitizado (BEISIEGEL, 2006). O autor aponta que o ensino público ganhou qualidade ao se estender à população, tornando possível que a escola atendesse jovens de qualquer nível social, tornando-se numa escola comum, aberta a todos.
Segundo o autor, esse alargamento das oportunidades reforçou a ideia de desenvolver uma democratização real da sociedade e que com essa transformação do ensino público, devemos reexaminar a dicotomia estabelecida entre qualidade e quantidade, pois, a expansão da educação significou uma indiscutível melhoria qualitativa do ensino.

Este processo trouxe novas e complexas exigências para a instituição escolar e seus profissionais e a necessidade de se adotar novas características pedagógicas e organizacionais diante desta nova demanda (LEITE; DI GIORGI, 2007). Os autores reforçam que a escola pública 
precisa realizar uma inclusão social com qualidade e para isso, é preciso valorizar as práticas existentes, criar novas práticas no trabalho em sala de aula, na elaboração do currículo, na gestão e no relacionamento entre a equipe escolar, alunos, pais e comunidade.

A relevância da gestão da escola fica em evidência, podendo articular e valorizar a participação dos pais na escola (LEITE; DI GIORGI, 2007). Entendemos que a concepção da gestão democrática pode proporcionar essa participação dos pais, pois, se apoia no exercício da democracia que será legitimada na prática com uma real participação desses sujeitos na escola, dialogando para buscar atingir os objetivos da escola.

A concepção de gestão democrática é assegurada na legislação vigente como um dos princípios na organização do trabalho nas escolas públicas, conforme apresentado pela Constituição Federal (BRASIL, 1988), pela LDBEN no 9.394 (BRASIL, 1996) e pela Lei no 13.005 (BRASIL, 2014).

No campo teórico, o conceito dessa gestão é defendido por Souza (2009, p. 125-126), mostrando que ela é compreendida

[...] como um processo
político no qual as pessoas
que atuam na/sobre a escola
identificam problemas,
discutem, deliberam encaminham,
planejam, controlam e
acompanham, achóes
avaliam o conjunto das ações
voltadas ao desenvolvimento
da própria escola na busca da
solução daqueles problemas.
Esse processo, sustentado no
diálogo, na alteridade e no
reconhecimento às
especificidades técnicas das
diversas funções presentes na
escola, tem como base a
participação efetiva de todos
os segmentos da comunidade
escolar, o respeito às normas
coletivamente construídas
para os processos de tomada
de decisões e a garantia de
amplo acesso às informações
aos sujeitos da escola.

Diante disso, ao considerar a escola como uma organização, vimos a necessidade de que todos os sujeitos envolvidos com ela estejam interrelacionados e que a comunicação e o diálogo seja concreta, de modo a viabilizar a organização e melhor planejamento das atividades. Parte desse diálogo pode ser concretizada por meio de um colegiado em que, com "[...] a prática da participação nos órgãos deliberativos da escola, os pais, os professores, os alunos, vão aprendendo a sentir-se responsáveis pelas decisões que os afetam num âmbito mais amplo da sociedade." (LIBÂNEO, 2003, p. 114).

Nessa linha de pensamento, ressaltamos que o Projeto Político Pedagógico (PPP) pode se constituir na base para essa participação, assim como a Associação de Pais e Mestres (APM) e o Conselho de Escola (CE). Araújo (2006) reforça que um PPP baseado no trabalho coletivo, nos princípios da autonomia, da gestão democrática e que seja articulado localmente pode alcançar a qualidade do ensino. Dessa forma, o PPP mostrase uma atividade fundamental para 0 desenvolvimento do trabalho coletivo e assim, alcançar o sucesso escolar.

Tendo isto em vista, entendemos que um fator dificultador para esse trabalho coletivo entre os diferentes segmentos na escola é uma gestão verticalizada, que não abre espaço para a colaboração. Essa gestão pode deixar de lado a coletividade na elaboração do PPP e consequentemente, a não participação dos pais, sendo esta uma parte necessária para a contribuição na busca do alcance dos objetivos da escola.

A motivação em me aprofundar nessa temática originou-se a partir das reflexões propiciadas por estudos e pesquisas anteriores, realizadas desde o $2 \circ$ ano da minha graduação em Pedagogia no ano de 2011. Nesse período participei de projetos do Núcleo de Ensino/PROGRAD (Pró-reitoria de Graduação) sob a coordenação da Profa Dra Yoshie Ussami Ferrari Leite.

Em um desses estudos (LEITE et al., 2012), utilizamos a teoria das representações sociais para compreender o olhar das diretoras escolares do município de Regente Feijó-SP a respeito da escola. Suas representações sociais sobre a "escola pública de hoje" e "aluno da escola pública de hoje" apontaram que a família é ausente no processo escolar e que a falta de apoio destes sujeitos faz com que o aluno seja desinteressado, culpabilizando-os em certa medida, pelo insucesso escolar. No ano seguinte (LEITEet al., 2014), ao realizar uma experiência de pesquisa-ação com as gestoras escolares do mesmo município, disseram que a maior dificuldade na unidade escolar era a 
falta de participação e compromisso dos pais dos alunos. Foi então que me questionei sobre a necessidade de compreender a percepção dos pais sobre a participação na escola.

Entendemos que a escola não pode ser pensada apenas pelos sujeitos que convivem no seu espaço cotidianamente, mas também, por aqueles que matricularam seus filhos naquela escola, os quais precisam estabelecer um viés de participação com ela. Percebemos então como um problema necessário a ser investigado, o de verificar junto aos pais dos alunos a sua percepção em relação à participação na escola.

Cabe ressaltar que o contexto das famílias tiveram mudanças profundas nas últimas décadas e passaram a coexistir diversas situações na constituição familiar (CASASSUS, 2007). Por essa razão, esclarecemos que nesta pesquisa quando usamos o termo "pais de alunos", estamos nos referindo aos responsáveis familiares dos alunos, isto é, pais, mães, tios, avós, envolvendo as diferentes situações familiares existentes.

Diante dessa argumentação, esta pesquisa tem como objetivo geral o de compreender a percepção dos pais sobre a participação em uma Escola Estadual em Presidente Prudente. Contudo, neste estudo apresentamos um recorte da pesquisa, com o objetivo de investigar a produção acadêmica sobre a percepção dos pais sobre participação na escola.

\section{METODOLOGIA}

A pesquisa foi desenvolvida com base na abordagem qualitativa e como procedimento utilizamos a pesquisa bibliográfica (MARCONI; LAKATOS, 2010). O tipo de fonte utilizada para esta pesquisa foram dissertações e teses defendidas nos Programas de Pós-Graduação em Educação (PPGEs) de Instituições de Ensino Superior (IES) credenciados pela Coordenação de Aperfeiçoamento de Pessoal de Nível Superior (CAPES). A pesquisa foi realizada em âmbito nacional e selecionou PPGEs com conceito de 4 a 7 (resultado da avaliação trienal de 2011-2013 ).

Como delimitação temporal, estabelecemos o foco da pesquisa nas publicações entre os anos de 2003 a 2013. Realizamos esta busca durante os meses de Março de 2014 a Janeiro de 2015 diretamente no banco de dados nos sites das próprias IESs.

A pesquisa foi guiada pela busca de seis descritores relacionados ao objeto de estudo desta pesquisa, tais como: "relação dos pais com atividades dentro da escola", "projeto político- pedagógico", "percepção dos pais sobre a escola pública", "APM", "CE" e "gestão democrática", dos quais buscamos identificar os trabalhos pelos títulos e também pelas palavras-chave.

Após a organização dos dados por descritor, realizamos a análise de conteúdo (BARDIN, 2010) de todos os resumos, por ser considerado um instrumento de trabalho para selecionar as obras mais condizentes com o tema, pois possui os elementos norteadores da pesquisa (MARCONI; LAKATOS, 2010). Para tanto, durante a análise dos resumos, elaboramos diversas categorias a fim de sintetizar as temáticas abordadas nas pesquisas.

\section{RESULTADOS}

Realizamos a consulta em 74 PPGEs, em que 30 são de instituições particulares, 29 de instituições federais, 14 de estaduais e uma municipal. Dentre estes 74 PPGEs encontramos trabalhos com os descritores em 58, correspondendo: UNICAMP, UFSCAR, USP, FFC/UNESP, FCT/UNESP, UNESP/RC, FCL/UNESP, UNIMEP, UMESP, UNISO, UNINOVE, PUC-SPCurrículo, PUC-SP-História, política e sociedade, PUC-SP-Psicologia da educação, CUML, PUCCAMP, UNICID, UNISANTOS, UFRJ, UFF, PUC-RIO, UNESA, UCP-RJ, UFES, UFMG, UFJF, UFU, PUC-MG, UFPR, PUC-PR, UTP, UEL, UFSC, UFRGS, UFSM, UFPEL, PUC-RS, UNISINOS, UPF, UNILASALLE, UFMT, UCB, UNB, UFMS, UCDB, UFGD, UFG, PUC-GOIÁS, UFAL, UFBA, UNEB-Educação, UNEB-Política Pública, UFC, UFPB-JP, UFPE, UFPI, UFRN, UFPA.

Observamos que uma quantidade significativa de PPGEs se concentram no Estado de São Paulo (19). Em decorrência disso, verificamos que a região Sudeste conta com o maior número de PPGEs, totalizando 32. Em seguida, a região Sul (20 PPGEs), na região Nordeste (12), no Centrooeste (8) e na região Norte (2).

Nestes 58 PPGEs, foram consultadas 18.472 dissertações e 5.452 teses, somando um total de 23.924 trabalhos. A partir da busca com os descritores foram encontradas 234 dissertações, o que representa $1,26 \%$ das dissertações consultadas e 43 teses, representando $0,78 \%$ das teses consultadas, totalizando então, 277 trabalhos (1,15\%). Além deste total de trabalhos, encontramos outros 10, porém, foram desconsiderados por não possuírem o resumo, item fundamental para a identificação do trabalho e a análise inicial (MARCONI; LAKATOS 2010).

Estes dados são referentes aos 58 PPGEs que encontramos dissertações e teses por meio 
dos descritores. Os outros 16 PPGEs que não encontramos nenhum trabalho foram: USF, UERJ, UFRRJ, UNIRIO, UEM, UEPG, UDESC, UNIVALI, FURB, UNIJUÍ, UCS, ULBRA, UECE, FUFSE, UNIT-SE e UFAM. A quantidade de trabalhos pesquisados nos Programas mencionados, totalizam 2.524 dissertações e 169 teses. Ao somar esse dado com total apresentado na tabela anterior, pesquisamos 20.996 dissertações e 5.621 teses, resultando em 26.617 trabalhos pesquisados.

Retomando aos dados dos trabalhos encontrados, fizemos uma organização por descritor. Com o descritor "Gestão Democrática" foram encontrados 183 trabalhos, sendo 155 dissertações e 28 teses, considerada uma quantia significativa de trabalhos nessa área. Com o descritor "Projeto Político-Pedagógico" obtivemos 54 trabalhos, correspondendo em 42 dissertações e 12 teses. Por meio do descritor "Associação de Pais e Mestres" encontramos 3 dissertações e com "Conselho de Escola" encontramos duas dissertações e uma tese.

Localizamos também mais de um descritor por trabalho, como: "Projeto Político-Pedagógico" e "Gestão Democrática", com um total de 17 trabalhos, 16 dissertações e uma tese; "Gestão Democrática" e "Conselho de Escola" com 14 trabalhos, 13 dissertações e uma tese; "Associação de Pais e Mestres" e "Conselho de Escola" encontramos duas dissertações e por último, uma dissertação envolvendo os descritores "Projeto Político-Pedagógico", "Conselho de Escola" e "Gestão Democrática". Com os outros dois descritores (relação dos pais com as atividades dentro da escola e percepção dos pais sobre a escola pública) não encontramos nenhum trabalho.

\section{DISCUSSÃO}

Percebemos nos trabalhos analisados que foram realizadas pesquisas sobre os aspectos legais, relatos de diversas investigações e estudos teóricos. No que se refere aos trabalhos com o descritor "Gestão Democrática", encontramos temáticas bastante diversificadas. Dentre elas, foi tratada a construção da gestão democrática na escola, a participação da comunidade escolar, a democratização, a implantação de órgãos, políticas e fóruns, os colegiados escolares, a organização da escola, eleições de diretores, sobre o coordenador pedagógico, o uso da tecnologia, as finanças da escola, a formação continuada, as legislações, a avaliação externa, o cotidiano escolar, as relações de poder, o trabalho do supervisor, a autonomia das escolas, a descentralização, a autogestão, a reorientação curricular, o abuso sexual, o trabalho infantil doméstico, a interação escola e família, a inclusão e a auto avaliação institucional.

Dentre o total de 215 trabalhos com o descritor "Gestão Democrática", dois nos chamou a atenção, pois, envolveram entrevistas com pais de alunos para verificar suas percepções. No entanto, ambos consideraram outro foco, como o funcionamento dos conselhos escolares e a organização do trabalho pedagógico na escola.

Com o descritor "Projeto PolíticoPedagógico" os trabalhos trataram da construção do PPP, da educação inclusiva, das políticas educacionais, da participação da comunidade escolar e local, da formação de professores, a educação ambiental, discursos sobre conhecimento escolar e a produção de currículo. Embora foram encontrados diversos trabalhos que analisaram o PPP da escola, nenhum deles tiveram a pretensão de investigar nesse documento quais os espaços de participação dos pais. Percebemos que o PPP foi abordado de diversas formas nos trabalhos no que tange a participação dos professores, funcionários e alunos, não evidenciando preocupação quanto aos pais dos alunos.

Dos trabalhos sobre a "Associação de Pais e Mestres" e "Conselho de Escola", foram investigadas as possíveis contribuições da APM, a participação dos professores, alunos, pais, comunidade e a formação política de conselheiros. Dentre todos os trabalhos, apenas dois tiveram o foco na participação dos pais. Um deles buscou identificar as causas da pequena participação e o outro, como essa participação é vista pelos profissionais da educação, não tratando especificamente de investigar junto aos pais a percepção que possui sobre sua participação.

\section{CONCLUSÃO}

No que tange a investigação junto aos PPGEs por meio da leitura dos 277 resumos das dissertações e das teses, constatamos alguns pontos específicos que possuem relação com nossa investigação sobre a percepção dos pais sobre a participação na escola. Percebemos que essa temática não foi mencionada nesses resumos,contudo, não se descarta a possibilidade de que a percepção desses sujeitos foi abordada no decorrer de algum trabalho, considerando que não foram lidos na íntegra, mas sim, apenas os resumos.

Por meio dessa pesquisa, percebemos como um desafio a análise dos resumos, pois, nem 
sempre trazem todos os dados da pesquisa, dificultando a compreensão do leitor sobre o trabalho desenvolvido. Isso também pode de certa forma, desvalorizar o trabalho do autor empreendido durante a pesquisa.

Entendemos que essa pesquisa bibliográfica constituiu-se num reforço, contribuindo para a compreensão mesmo que parcial das pesquisas realizadas sobre a temática, não sendo uma repetição do que já foi pesquisado sobre o assunto, mas, com a pretensão de propiciar o estudo do tema e chegar a novas conclusões (MARCONI; LAKATOS, 2010).

A partir disso, entendemos que investigar a percepção dos pais sobre a participação na escola pode apresentar elementos valiosos para a compreensão desta relação, a participação dos pais na escola em busca de uma gestão democrática. Temos que considerar também, que os reflexos dessas percepções a respeito da participação podem possibilitar que os profissionais da escola vislumbrem uma nova compreensão acerca dos pais dos alunos e assim, busquem efetivar um trabalho cada vez mais voltado para o exercício da democracia em busca da melhoria da qualidade da escola pública.

\section{REFERÊNCIAS}

ARAÚJO, E. S. O projeto pedagógico como (des) encadeador do trabalho coletivo na escola. Revista Educação: teoria e prática, Rio Claro, v.14, n. 26, p. 95-111, jan./jun., 2006. p. 95-111.

BARDIN, L. Análise de Conteúdo. 4. ed. Lisboa/Portugal: Loyola, 2010.

BEISIEGEL, C. R. Relações entre a quantidade e a qualidade no ensino comum. In: A

Qualidade do Ensino na Escola Pública. Brasília: Liber Livro, 2006. p. 111-122.

BRASIL. Constituição (1988). Constituição da

República Federativa do Brasil. Disponível em: <http://www.planalto.gov.br/ccivil_03/Constituica o/Constituicao.htm >. Acesso em 20 jan. 2015.

BRASIL. Lei no 9.394, de 20 de Dezembro de 1996. Dispõe sobre as diretrizes e bases da educação nacional. Disponível em: <http://www.planalto.gov.br/ccivil_03/LEIS/L4024. htm>. Acesso em 09 jun. 2015.

BRASIL. Lei no 13.005, 24 de Junho de 2014. Aprova o Plano Nacional de Educação - PNE e dá outras providências. Disponível em: <http://www.planalto.gov.br/ccivil_03/LEIS/L4024. htm>. Acesso em 10 jan. 2015.

CASASSUS, J. A escola e a desigualdade. 2. ed. Brasília: Líber Livro, UNESCO, 2007.
LEITE, Y. U. F.; DI GIORGI, C. A. G. Ressignificando a função da escola pública e do professor nos dias de hoje: alguns apontamentos. In: JUNIOR, C. A. S.; ARENA, D. B.; LEITE, Y. U. F. (Orgs.). Pedagogia Cidadã: Cadernos de Formação: Organização e Gestão do Trabalho na Escola. 2. ed. São Paulo: UNESP, Pró Reitoria de Graduação, 2007. p. 5-12.

LEITE, Y. U. F. et al. Um estudo sobre as representações sociais dos gestores escolares da rede municipal de ensino de Rancharia/SP e Regente Feijó/SP. In: PINHO, S. Z.; OLIVEIRA, J. B. B. (Orgs.). Núcleos de Ensino da Unesp [recurso eletrônico]: artigos dos projetos realizados em 2011. São Paulo: Cultura Acadêmica, 2012. v. 5. p. 76-93. Disponível em: $<$ http://www.unesp.br/portal\#!/prograd/e-livrosprograd/>. Acesso em 20 mar. 2015.

LEITE, Y. U. F. et al. Uma experiência de pesquisaação junto aos gestores do município de Regente Feijó/SP: relação entre escola e comunidade. In: COLVARA, L. D.; OLIVEIRA, J. B. B. (Orgs.). Núcleos de Ensino da Unesp [recurso eletrônico]: Artigos 2012: Políticas Públicas e Organização Escolar. São Paulo: Cultura Acadêmica, 2014, v. 5, p. 132-152. . Disponível em: $<$ http://www.unesp.br/portal\#!/prograd/e-livrosprograd/>. Acesso em: 20 mar. 2015.

LIBÂNEO, J. C. A identidade profissional dos professores e o desenvolvimento de competências. In: __ Organização e Gestão da Escola: teoria e prática. 4. ed. Goiânia: Alternativa, 2003. p. 73-81.

MARCONI, M. A.; LAKATOS, E. M. Fundamentos de Metodologia científica. 7. ed. São Paulo: Atlas, 2010.

SOUZA, Â. R. Explorando e construindo um conceito de gestão escolar democrática. Educação em Revista, Belo Horizonte, v. 25, n. 3, p. 123-140, dez. 2009. https://doi.org/10.1590/S010246982009000300007

Recebido para publicação em 24/08/2016

Revisado em 28/08/2016

Aceito em 31/08/2016 